\title{
Effects of Dried Aloe Vera Gel and Diclofenac on Sodium and Potassium Homeostasis: An Experimental Study on Hypertensive Rats
}

\author{
Nadeem Yaqoob ${ }^{1}$, Abdul Qudoos Arain ${ }^{2}$, Mufakhara Fatimah ${ }^{3}$, Samina Kausar ${ }^{4}$, Sadia Chiragh ${ }^{4}$ \\ ${ }^{1}$ Associate Professor, Pharmacology, Niazi Medical and Dental College, Sargodha \\ ${ }^{2}$ Professor, Pharmacology, HBS Medical and Dental College, Islamabad \\ ${ }^{3}$ Assistant Professor, Pharmacology, Sahara Medical College, Narowal \\ ${ }^{4}$ Professor, Pharmacology, Al-Aleem Medical College, Lahore
}

\begin{abstract}
A BSTRACT
Background: Anti-inflammatory role of Aloe vera gel is well established. Diclofenac is extensively used for acute and chronic inflammation. The present study was conducted to compare dried Aloe vera gel and diclofenac effects on sodium and potassium balance in hypertensive rats.

Material and Methods: This experimental study was conducted at Sargodha Medical College from May to November 2016. Twenty-four healthy male Sprague Dawley rats 7-8 weeks of age were included in study. Any unhealthy-looking rat was excluded from the study. Rats were equally and randomly divided into four groups Normal control (group A), Model control (group B), Aloe vera (group C) \& Diclofenac (group D). Hypertension was induced by a $20 \%$ sucrose diet in all groups except group A in 8 weeks' time. Group B, C \& D received distilled water and Aloe vera dried gel 400 $\mathrm{mg} / \mathrm{kg} \&$ diclofenac powder $12 \mathrm{mg} / \mathrm{kg}$ body weight respectively orally between 8 to 10 weeks. Serum and urine analysis was performed for hematocrit, sodium, and potassium concentrations at zero, eight and ten weeks. Twentyfour-hour urinary sodium excretion was calculated. Data was analyzed using Graph Pad Prism version 6.

Result: After 2-week administration of aloe vera and diclofenac powder, serum potassium significantly decreased in Group C $(p<0.001)$ while increased in Group B and D $(p<0.001)$ as compared to group A. Urinary sodium concentration and excretion increased significantly in Group C $(p<0.01)$ as compared to Group A whereas result of Group D was insignificant. No significant change in serum sodium and hematocrit of any group was observed.

Conclusion: Aloe vera causes less sodium retention than diclofenac but decreases serum potassium contrary to the effect of diclofenac in hypertensive rats.

Keywords: Aloe vera, Diclofenac, Electrolyte, Hematocrit, Hypertension

Authors' Contribution:

${ }^{4}$ Conception; Literature research;

manuscript design and drafting; 1,2, Critical Email:qudoospk@gmail.com

analysis and manuscript review; ${ }^{3}$ Data

analysis; Manuscript Editing.

Correspondence:

Abdul Qudoos Arain

Article info:

Received: January 5, 2021

Accepted: August 30, 2021
\end{abstract}

Cite this article. Yaqoob N, Arain AQ, Fatimah M, Kausar S, Chiragh S. Effects of Dried Aloe Vera Gel and Diclofenac on Sodium and Potassium Homeostasis: An Experimental Study on Hypertensive Rats. J Islamabad Med Dental Coll. 2021; 10(3): 133-139. Doi:

Funding Source: PGMI

Conflict of Interest: Nil 10.35787/jimdc.v10i3.658

\section{Introduction}

NSAIDs are the most prescribed agents in Pakistan for controlling inflammation, pain and fever. The main action of these agents is to suppress prostaglandin (PG) synthesis; by inhibiting the enzyme cyclooxygenase (COX-I\&II). COX-I enzyme of kidneys plays a physiological role and controls hemodynamic and glomerular filtration rate (GFR), while COX-II is an inducible enzyme responsible for 
cell injury or inflammation. This enzyme is also present in kidneys and affects electrolytes and water excretion hence regulates intravascular volume. Decreased activity of cyclooxygenase enzymes by NSAIDs causes hyperkalemia and sodium and water retention that causes edema hypertension, and kidney damage. ${ }^{1,2}$

NSAIDs other than affecting the kidneys also cause gastric and duodenal ulceration, exacerbate asthma symptoms, and increase bleeding tendency. NSAIDs like diclofenac have more potential to harm older people due to renal and cardiovascular risk. They carry a threat of chronic decrease of GFR as well as acute kidney damage. ${ }^{3}$ According to Liew.et al., continuous use of NSAIDs is associated with the risk of hypertension in 12 percent of individuals as compared to non-use or limited use of NSAIDs. ${ }^{4}$

Aloe vera, a water-storing and drought-tolerant plant has many therapeutic effects including antiinflammatory, immunomodulatory, hypoglycemic, anticancer, gastro-protective and antimicrobial properties. Due to these vast pharmacological effects; Aloe vera has been employed for several commercial applications. ${ }^{5}$ It can be separated into two basic products; latex, a bitter yellow exudate derived from the outer skin of the leaves which occupy approximately $20-30 \%$ of the weight of the whole leaf, and gel, which is a transparent mucilage material derived from the pulp of the leaves. ${ }^{6}$ This mucilaginous part of Aloe vera is traditionally used in different inflammatory disorders. ${ }^{7}$

The anti-inflammatory activity of this medicinal plant justifies its use in dermal inflammatory disorders and joint diseases, particularly in elderly patients. In this age group, the use of NSAIDs is limited because of their documented adverse effect on sodium \& water retention and electrolyte imbalance. There is insufficient data on safety of Aloe vera regarding sodium and potassium homeostasis especially in hypertensive subjects.

The purpose of this study is to evaluate the use of Aloe vera and its comparison with diclofenac on the hematocrit and electrolyte (sodium and potassium) balance of hypertensive rats. This research can provide data on safety profile of

Aloe vera to be used for future human studies on hypertensive patients.

\section{Material and Methods}

After approval from the ethical committee, this animal experimental study was conducted at Sargodha Medical College between May and November 2016. Twenty-four Sprague Dawley rats weighing between 235-380 $\mathrm{g}$, according to inclusion criteria of 7-8 weeks age and male gender were obtained from the University of Agriculture Faisalabad. Unhealthy-looking rats were excluded. Rats were randomly divided by lottery method into four equal groups: Normal control (Group A), Model Control (Group B), Aloe vera group (Group C) and Diclofenac group (Group D). They were kept in the college animal facility in iron cages for two weeks for acclimatization. Room temperature was maintained at $25 \pm 5^{\circ} \mathrm{C}$. A light and dark cycle of 12 hours was followed, and animals were given free access to food and water. Rats in Group A were given normal rat chow throughout the study period, whereas all the other groups were given normal rat chow containing sucrose $(20 \% \mathrm{w} / \mathrm{w})$ to induce hypertension, ${ }^{8}$ which was induced in all three groups in eight weeks. Systolic blood pressure $\geq 140 \mathrm{~mm} \mathrm{Hg}$ was considered hypertension ${ }^{9}$. After induction of hypertension at $8^{\text {th }}$ week, Group B was given distilled water $0.5 \mathrm{ml}$, and Group $\mathrm{C}$ was given Aloe vera gel powder $400 \mathrm{mg} / \mathrm{kg}$ body weight, ${ }^{10}$ and Group D was given diclofenac powder $12 \mathrm{mg} / \mathrm{kg}$ body weight by the oral route as a single morning dose for two weeks. ${ }^{11}$

Plants were purchased from a local nursery and identified by the Botany Department of Sargodha University. After washing the Aloe vera leaves and draining the yellow juice, the pulp was removed, mixed in a blender, filtered, air-dried and the resultant dried gel was stored at $4{ }^{\circ} \mathrm{C}^{10}$. Yield with reference to the whole leaf was $0.14 \%$. The fresh 
solution was prepared daily by dissolving $400 \mathrm{mg}$ in $5 \mathrm{ml}$ distilled water.

The body weight and blood pressure of animals were recorded at baseline and then weekly throughout the study. Systolic blood pressure was measured by tail-cuff, ${ }^{8}$ using a non-invasive blood pressure controller (ML125R) attached to the computer-based data recording system (Power lab).

Twenty-four-hour urine was collected in a glass container by keeping each animal in a separate cage at 0,8 , and 10 weeks. Urine sodium concentration and volume were measured and 24hour urinary excretion was calculated. After urine collection, two $\mathrm{ml}$ of blood was drawn through cardiac puncture; one $\mathrm{ml}$ blood was put in EDTA for determination of hematocrit and one $\mathrm{ml}$ in gel \& clot activator vacutainer. To separate serum, blood was centrifuged at $5000 \mathrm{rpm}$ for three minutes. Serum sodium and potassium levels were estimated by a flame photometer (SEAC P-10) and hematocrit by a hematology analyzer (Sysmex KX21).
Data was analyzed using Graph Pad Prism version 6. Normality was tested by the Shapiro-Wilk normality test and data was presented as mean \pm SD. Normally distributed data was compared using ANOVA. Changes in parameters at different times in each group were compared by t-test. Post hoc Tukey's test was applied for comparison among groups. A p-value of $\leq 0.05$ was considered significant.

\section{Results}

During the first 8 weeks, body weight, as well as systolic blood pressure, increased significantly ( $p$ value $<0.001)$ in groups receiving sucrose $\operatorname{diet}(B, C$ \& D) as compared to Group A while after two weeks, blood pressure increased by 2, 4, 3 and 17 $\mathrm{mm} \mathrm{Hg}$ in groups A, B, C and D respectively. However, no significant change was seen in hematocrit of any group during the study period (Table 1). Serum sodium concentration remained within the normal range with non-significant differences in readings throughout the study

\begin{tabular}{|c|c|c|c|c|c|c|c|c|c|}
\hline \multirow[t]{3}{*}{ Groups } & \multicolumn{3}{|c|}{ Hematocrit (\%) } & \multicolumn{3}{|c|}{ Serum $\mathrm{Na}(\mathrm{mEq} / \mathrm{L})$} & \multicolumn{3}{|c|}{ Urine Vol. (ml) } \\
\hline & 0 Week & 8 Weeks & 10 Weeks & 0 Week & 8 Weeks & 10 Weeks & 0 Week & 8 Weeks & 10 Weeks \\
\hline & $\begin{array}{l}\text { Mean } \\
\pm S D\end{array}$ & $\begin{array}{l}\text { Mean } \\
\pm S D\end{array}$ & $\begin{array}{l}\text { Mean } \\
\pm S D\end{array}$ & $\begin{array}{l}\text { Mean } \\
\pm S D\end{array}$ & $\begin{array}{l}\text { Mean } \\
\pm S D\end{array}$ & $\begin{array}{l}\text { Mean } \\
\pm S D\end{array}$ & $\begin{array}{l}\text { Mean } \\
\pm S D\end{array}$ & $\begin{array}{l}\text { Mean } \\
\pm S D\end{array}$ & $\begin{array}{l}\text { Mean } \\
\pm S D\end{array}$ \\
\hline $\begin{array}{l}\text { Normal } \\
\text { Control(A) }\end{array}$ & $\begin{array}{l}37.83 \pm 3 \\
.06\end{array}$ & $38 \pm 3.9$ & $\begin{array}{l}38.5 \pm 3.7 \\
3\end{array}$ & $\begin{array}{l}120.83 \pm 1 \\
4.2 \\
\end{array}$ & $\begin{array}{l}118.17 \pm \\
8.38\end{array}$ & $\begin{array}{l}123 \pm 12 . \\
17\end{array}$ & $\begin{array}{l}5.77 \pm 1 . \\
05\end{array}$ & $\begin{array}{l}5.83 \pm 0 . \\
41\end{array}$ & $\begin{array}{l}5.87 \pm 0 . \\
60\end{array}$ \\
\hline $\begin{array}{l}\text { Model } \\
\text { Control(B) }\end{array}$ & $\begin{array}{l}37.67 \pm 2 \\
.8\end{array}$ & $39 \pm 3.29$ & $\begin{array}{l}38.5 \pm 2.4 \\
3\end{array}$ & $\begin{array}{l}117.83 \pm 3 \\
.37\end{array}$ & $\begin{array}{l}116.67 \pm \\
16.94 \\
\end{array}$ & $\begin{array}{l}117.67 \pm \\
6.62\end{array}$ & $\begin{array}{l}5.72 \pm 1 . \\
80\end{array}$ & $\begin{array}{l}5.70 \pm 0 . \\
28\end{array}$ & $\begin{array}{l}5.77 \pm 0 . \\
23\end{array}$ \\
\hline $\begin{array}{l}\text { Aloe vera } \\
\text { (C) }\end{array}$ & $\begin{array}{l}36.67 \pm 3 \\
.39 \\
\end{array}$ & $\begin{array}{l}39.33 \pm 6 \\
.22 \\
\end{array}$ & $\begin{array}{l}38.67 \pm 4 . \\
27\end{array}$ & $\begin{array}{l}119.33 \pm 7 \\
.31 \\
\end{array}$ & $\begin{array}{l}107.33 \pm \\
30.16\end{array}$ & $\begin{array}{l}124.33 \pm \\
38.73 \\
\end{array}$ & $\begin{array}{l}5.40 \pm 2 . \\
69\end{array}$ & $\begin{array}{l}5.50 \pm 0 . \\
35\end{array}$ & $\begin{array}{l}5.40 \pm 0 . \\
94\end{array}$ \\
\hline $\begin{array}{l}\text { Diclofenac } \\
\text { (D) }\end{array}$ & $\begin{array}{l}37.17 \pm 2 \\
.93\end{array}$ & $\begin{array}{l}39.5 \pm 3 . \\
45\end{array}$ & $\begin{array}{l}37.17 \pm 2 . \\
48\end{array}$ & $\begin{array}{l}125.17 \pm 1 \\
1.07\end{array}$ & $\begin{array}{l}118 \pm 4.2 \\
4\end{array}$ & $\begin{array}{l}115.83 \pm \\
13.14\end{array}$ & $\begin{array}{l}5.63 \pm 2 . \\
37\end{array}$ & $\begin{array}{l}5.60 \pm 0 . \\
51\end{array}$ & $\begin{array}{l}5.17 \pm 0 . \\
59\end{array}$ \\
\hline ANOVA & 0.909 & 0.934 & 0.850 & 0.612 & 0.685 & 0.884 & 0.990 & 0.518 & 0.234 \\
\hline
\end{tabular}

Serum Potassium Concentration: Analysis by t-test within each group between 8 to 10 weeks revealed that serum potassium significantly decreased in Aloe vera group (Group $C$ ) and increased in diclofenac (Group D) and model control (Group B) groups with $p$-values $<0.001,<0.001$ and 0.008 respectively. At the end of study, serum potassium was significantly higher in model control and diclofenac groups as compared to normal control, while that of Aloe vera group was significantly lower versus all other groups as calculated by Tukey's test (Figure 1). 


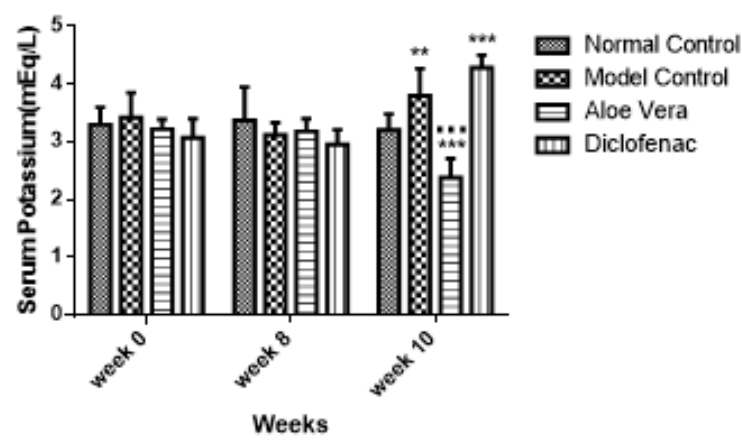

Figure 1: Effect of Aloe vera gel and diclofenac on serum potassium concentration (Mean \pm SD) of hypertensive rats $(n=6)$. Significance between groups calculated by Tukey's test.

*** p value $<0.001$ Versus Normal Control Group (A)

** $\quad$ p value $<0.01$ Versus Normal Control Group (A)

... p value $<0.001$ Versus Model Control (B) \&Diclofenac Group (D)

Urinary Sodium Concentration: Analysis by t-test within each group between 8 to 10 weeks revealed that urinary sodium concentration increased significantly in model group only ( $p$-value 0.038 ). At the end of study, urinary sodium concentration was highest in model group, followed by Aloe vera, diclofenac and normal group (Figure2).

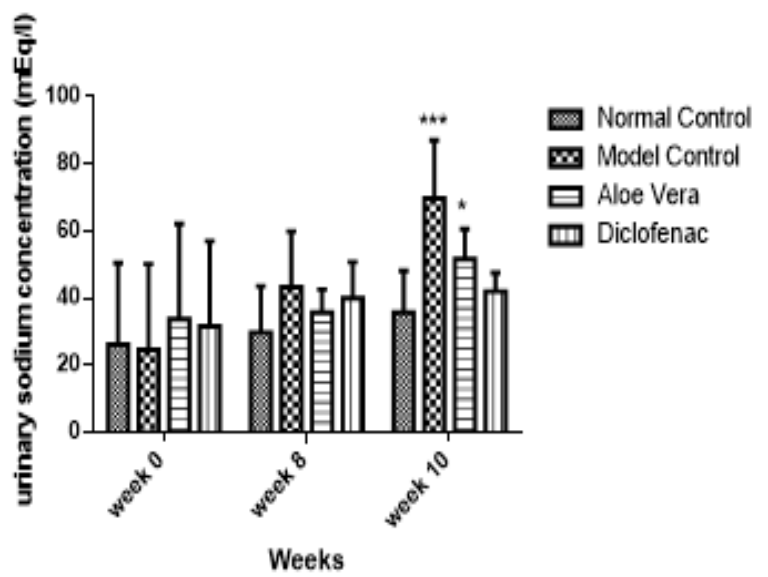

Figure 2: Effect of Aloe vera gel and diclofenac on urinary sodium concentration (Mean $\pm S D$ ) of hypertensive rats $(n=6)$ Significance between groups calculated by Tukey's test.

*** $\quad \mathrm{p}$ value $<0.001$ Versus Normal Control (A) \& Diclofenac Group (D)

* $\quad p$ value $<0.01$ Versus Normal Control (A) \& Model control Group (B)
Urinary volume was statically similar in all groups at all reading times (Table 1 )

Twenty-four Hour Urinary Sodium Excretion: Results were parallel to urinary sodium concentration, i.e., a significant increase from 8-10 weeks period in model group with $\mathrm{p}$-value 0.016 (ttest). At end of 10th week, it was highest in model group followed by Aloe vera, diclofenac and normal group (Figure 3).

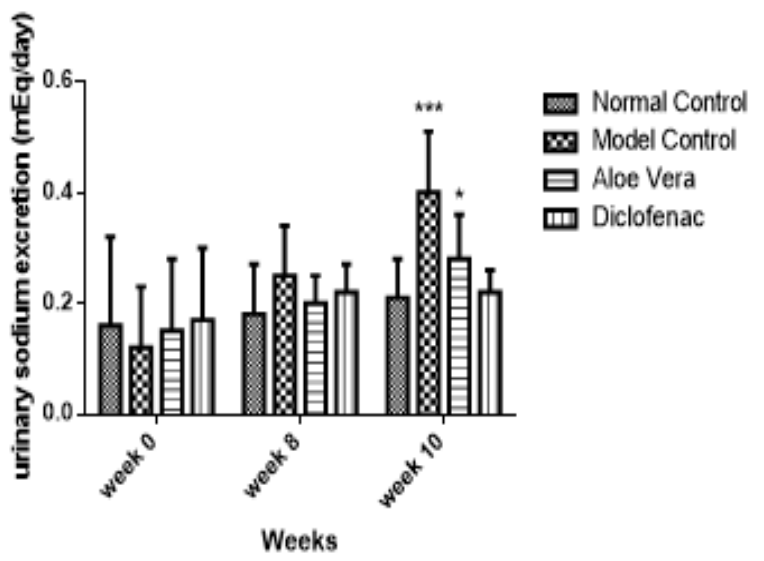

Figure 3: Effect of Aloe vera gel and diclofenac on urinary sodium excretion (Mean $\pm S D$ ) of hypertensive rats $(n=6)$ Significance between groups calculated by Tukey's test.

*** $\quad \mathrm{p}$ value $<0.001$ Versus Normal Control (A) \& Diclofenac Group (D)

* $\quad \mathrm{p}$ value $<0.01$ Versus Model control Group (B)

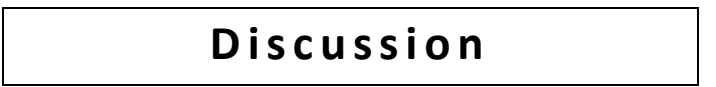

Nonsteroidal anti-inflammatory drugs like diclofenac are the most commonly used and prescribed drug in our society. NSAIDs are being prescribed in our routine medical practice as analgesics, antipyretics and anti-inflammatory agents. ${ }^{2}$ The pharmacological effects of NSAIDs on body organs depend upon the concentration and the time-duration of their use. The most affected organ is kidney, and therefore high doses or prolonged treatment can increase morbidity, especially in geriatric patients, as they already have declined renal functions. Moreover, these drugs disturb the normal electrolyte balance and affect the response of some diuretics which is expressed 
as chronic retention of sodium and potassium. According to Aljadheyet al., NSAID use is linked with a small increase in systolic blood pressure in hypertensive patients. ${ }^{12}$

The role of Aloe vera gel as an anti-inflammatory agent is well established. Aloe vera controls inflammatory reactions through different mechanisms. One of these mechanisms is closely associated with NSAIDs, i.e., inhibition of arachidonic acid pathway. ${ }^{13}$ This study was designed with an objective to compare the effects of Aloe vera gel and diclofenac on electrolyte balance in a hypertensive rat model. For this purpose, $20 \%$ sucrose diet was given to the rats, which successfully induced hypertension within the desired period of eight weeks. The results of this study clearly indicate that Aloe vera causes potassium loss paradoxical to the effect of diclofenac which causes potassium retention. Furthermore, it causes less sodium retention than diclofenac.

Diclofenac increases serum potassium concentration, possibly by inhibiting prostaglandin synthesis, resulting in decreased renin secretion, which reduces the level of aldosterone in the blood. ${ }^{14}$ Another mechanism of elevated serum potassium could be decreased synthesis of $\mathrm{PGI}_{2}$ which stimulates renal juxtaglomerular cells to release renin and consequently aldosterone. The inhibition of $\mathrm{PGI}_{2}$ by NSAIDs also causes decreased distal renal tubular flow and hyperkalemia. ${ }^{2} A n$ Increase in the model control group may be linked to decreased sodium reabsorption as compensatory mechanism leading to increased potassium reabsorption in exchange. Aloe vera group exhibited a significant decrease in serum potassium from 8-10 weeks. Saka et al. expressed an insignificant decrease in serum potassium level when Aloe vera was given to healthy rats for 28 days, ${ }^{15}$ while higher dose, i.e., $800 \mathrm{mg} / \mathrm{Kg}$ of chloroform extract of Aloe vera gel, significantly decreased serum potassium in healthy rats. ${ }^{16}$ This decrease in serum potassium may be an aldosterone-like effect of Aloe vera gel sterols. Contrary to these results, six weeks of treatment with $600 \mathrm{mg} / \mathrm{Kg}$ dose of Aloe vera gel has shown to produce no change in serum potassium of normal rats and increase in serum potassium of salt-loaded rats, ${ }^{17}$ which was considered to be due to increased exchange with sodium.

The Present research shows an insignificant decrease in serum sodium level of diclofenac group during 8-10-week period. Another study has shown similar results in which $15 \mathrm{mg} / \mathrm{kg}$ dose of diclofenac given for five days did not produce any significant change in serum sodium concentration of Wistar rats. ${ }^{18}$ Serum sodium level of Aloe vera group showed a non-significant rise which is supported by another study in which chloroform extract of Aloe vera has shown an insignificant rise in serum sodium after 14 days of treatment which became significant after 28 days. ${ }^{19}$ Saka et al. showed the opposite effects of Aloe vera extract, which significantly decreased serum sodium concentration when given for 28 days. ${ }^{15}$ These studies were performed on healthy rats; no study is available for effect of Aloe vera on hypertensive rats.

Urinary sodium concentration and 24-hour excretion increased in all groups during the 8-10week period, but this increase was significant only in the model control group and numerically negligible in the diclofenac group. At $10^{\text {th }}$-week, urinary sodium concentration and excretion were significantly higher in the model control group than all other groups which seems to be a normal compensatory mechanism, which is blunted with diclofenac treatment due to inhibition of renal prostaglandins. ${ }^{20}$ Aloe vera caused less blunting of this compensatory mechanism. The reason may be lesser inhibition of prostaglandins by Aloe vera as compared to diclofenac which acts mainly by inhibition of COX, while the anti-inflammatory activity of Aloe vera is due to multiple mechanisms. ${ }^{21}$ 
The hematocrit of hypertensive groups decreased insignificantly from $8^{\text {th }}$ to $10^{\text {th }}$ week of the experiment, but this decrease was numerically more in diclofenac-treated rats. Aycan et al. made the same observation when forty male Wistar rats were treated with diclofenac $(9 \mathrm{mg} / \mathrm{kg})$ intravenously, daily for five days. ${ }^{22}$ Sodium and fluid retention by diclofenac may be the reason for hematocrit decrease. Aloe vera did not affect hematocrit significantly in this study; Obeten et al. reinforced these effects of Aloe vera on hematology of Wistar rats. ${ }^{23}$

To sum up the results, serum potassium was significantly higher in diclofenac group and significantly lower in Aloe vera group. Moreover, there was more decline in urinary sodium concentration and excretion with diclofenac than with Aloe vera, although difference between the two was statistically insignificant. So ultimately these parameters show that diclofenac has the tendency to cause more salt and water retention than Aloe vera. This is one of few studies on the effect of Aloe vera on electrolyte balance and first one on hypertensive rats.

The study has limitations that doses of Aloe vera gel and diclofenac were selected from two different studies. The anti-inflammatory effect of these doses was not compared in the present research. One would have been more confident in declaring Aloe vera a better anti-inflammatory option; had it been done. Administration of experimental drugs for two weeks is a short duration and another limitation. Long-term use of Aloe vera may reveal more sodium retention, or further lowering of serum potassium may be more harmful than sodium retention. Examination of histological effects may give a more clear picture.

\section{Conclusion}

Aloe vera causes less sodium retention than diclofenac but decreases serum potassium contrary to the effect of diclofenac in hypertensive rats. No significant effect on hematocrit was seen. Further studies with different doses of Aloe vera and longer duration of intervention, as well as interaction with drugs, need to be conducted.

\section{Acknowledgment}

We appreciate Dr. Alamgeer, who allowed using the facility of Power Lab in the department of Pharmacy, University of Sargodha. We are grateful to Mr. Samiullah, the lecturer University of Sargodha for providing help in statistical analysis.

\section{Disclaimer}

Current manuscript is part of the MPhil thesis research

\section{Funding Disclosure}

Post Graduate Medical Institute (PGMI), Lahore

\section{References}

1. Abiola TS, Adebayo OC, Babalola O. DiclofenacInduced Kidney Damage in Wistar Rats: Involvement of Antioxidant Mechanism. Journal of Biosciences and Medicines. 2019;7(12):44. Doi: 10.4236/jbm.2019.712005

2. Lucas GNC, Leitão ACC, Alencar RL, Xavier RMF, Daher EDF, Silva Junior GBd. Pathophysiological aspects of nephropathy caused by nonsteroidal antiinflammatory drugs. Brazilian Journal of Nephrology. 2019;41(1):124-30. Doi: 10.1590/2175-8239-JBN2018-0107

3. Modig S, Elmståhl S. Kidney function and use of nonsteroidal anti-inflammatory drugs among elderly people: a cross-sectional study on potential hazards for an at risk population. Int J Clin Pharm. 2018;40(4):870-7. Doi: 10.1007/s11096-018-0598-8

4. Liew JW, Ward MM, Reveille JD, Weisman M, Brown $M A$, Lee $M$, et al. Nonsteroidal Antiinflammatory Drug Use and Association with Incident Hypertension in Ankylosing Spondylitis. Arthritis Care Res (Hoboken). 2020;72(11):1645-52. Doi: 10.1002/acr.24070

5. Maan AA, Nazir A, Khan MKI, Ahmad T, Zia R, Murid $M$, et al. The therapeutic properties and applications of Aloe vera: A review. Journal of Herbal Medicine. 2018; 12:1-10. Doi: 10.1016/j.hermed.2018.01.002

6. Minjares-Fuentes R, Femenia A. Nonvitamin and Nonmineral Nutritional Supplements: Academic 
Press; 2019. p. 145-52. Doi: 10.1016/B978-0-12812491-8.00020-5

7. Sánchez M, González-Burgos E, Iglesias I, GómezSerranillos MP. Pharmacological update properties of Aloe vera and its major active constituents. Molecules. 2020;25(6):1324. Doi: 10.3390/molecules25061324

8. Yaqoob N, Fatimah M, Naqvi F, Sarfraz J, Mushtaq S, Chiragh S. Comparative evaluation of aloe vera and diclofenac on body weight, blood pressure and renal function of hypertensive rats. 2021;35(1):39-44. Doi: 10.47489/p000s351z7821-6mc

9. Chobanian AV. Time to reassess blood-pressure goals. N Engl J Med. 2015;373(22):2093-5. Doi: 10.1056/NEJMp1513290

10. Shahriari $M$, Khaksari $M$, Bibak B, Ramshini $A$, Shahabi A: The Effects of Aloe Vera Extract on Brain Edema and Blood-Brain Barrier Permeability after Traumatic Brain Injury. The Neuroscience Journal of Shefaye Khatam. 2017 10;5(2):50-50.

11. Breganó JW, Barbosa DS, Kadri MZE, Rodrigues MA, Cecchini R, Dichi I. Comparison of selective and nonselective cyclooxygenase 2 inhibitors in experimental colitis exacerbation: role of leukotriene B4 and superoxide dismutase. Arq Gastroenterol. 2014;51(3):226-34. Doi: 10.1590/S0004-28032014000300012

12. Aljadhey $\mathrm{H}, \mathrm{Tu}$ W, Hansen RA, Blalock SJ, Brater DC, Murray MD. Comparative effects of nonsteroidal anti-inflammatory drugs (NSAIDs) on blood pressure in patients with hypertension. BMC Cardiovasc Disord. 2012;12(1):93. Doi: 10.1186/1471-2261-1293

13. Rahmani AH, Aldebasi $\mathrm{YH}$, Srikar S, Khan AA, Aly SM. Aloe vera: Potential candidate in health management via modulation of biological activities. Pharmacogn Rev. 2015;9(18):120-6. Doi: 10.4103/0973-7847.162118

14. Krishnan SK, Lepor NE. Acute and Chronic Cardiovascular Effects of Hyperkalemia: New Insights into Prevention and Clinical Management. Rev Cardiovasc Med. 2016. Doi: 10.3909/ricm17S1S0002
15. Saka W, Akhigbe R, Popoola O, Oyekunle O. Changes in serum electrolytes, urea, and creatinine in Aloe vera-treated rats. J Young Pharm. 2012;4(2):78-81. Doi: 10.4103/0975-1483.96620

16. Arain $A Q$, Hussain $M$, Chiragh $S$. Effect of different doses of aloe vera versus indomethacin on sodium and water retention in healthy rats. JPMI. 2017;31(3): 286-91.

17. Udefa AL, Archibong AN, Akwari AA, Leilei SA. Effect of Aloe vera gel on some haematological parameters and serum electrolytes in high salt loaded Wistar rats. MicroMedicine. 2018;6(2):69-77. Doi: 10.5281/zenodo.1318287

18. Barbosa CM, Sakate M, Camplesi AC, Vailati MdCF, Moraes LF, Takahira RK. Evaluations hematological and biochemical by the use of sodium diclofenac, meloxicam and firocoxib in rats. Braz J Vet Res Anim Sci. 2010:118-26.

19. Arain A, Hussain M, Muneer A, Chiragh S. Effect of chloroform extract of Aloe vera jell on sodium and water retention in rats. Biomedica. 2016;32(2):8992.

20. Ahmed AN and Daniel EF. Nonsteroidal AntiInflammatory Drugs, Disease-Modifying Antirheumatic Drugs, Nonopioid Analgesics, \& Drugs Used in Gout; Basic \& Clinical Pharmacology. 14th ed. New York: Katzung BG Mcgraw Hill Education; 2018. Chapter 36: 642-666.

21. Gebremeskel L, Bhoumik D, Sibhat GG, Tuem KB. In vivo wound healing and anti-inflammatory activities of leaf latex of aloe megalacantha baker (Xanthorrhoeaceae). Evid Based Complement Alternat Med;2018. Doi: 10.1155/2018/5037912

22. Aycan iÖ, Elpek Ö, Akkaya B, Kıraç E, Tuzcu H, Kaya $S$, et al. Diclofenac induced gastrointestinal and renal toxicity is alleviated by thymoquinone treatment. Food and Chemical Toxicology. 2018; 118:795-804. Doi: 10.1016/j.fct.2018.06.038

23. Obeten CE, Ani EJ, Ime AU, Kokelu AN, Edet O. Thermoxidized palm oil diet (TPO)-induced haematological derangements in rats is ameliorated by aloe vera and Garlic. The Journal of Phytopharmacology.2018;7(4):353-9. ISSN 2320480X 